\title{
Modeling of cosolvent and temperature effects on ethanolic extraction of pequi and murici seeds
}

\author{
Ana Cristina Moreira Andrade Araújo1, Érica Resende Oliveira ${ }^{1 *}$, Gabriel Ribeiro Carvalho', \\ Evandro Galvão Tavarez Menezes ${ }^{1,2}$, Fabiana Queiroz ${ }^{1}$
}

${ }^{1}$ Department of Food Science, Federal University of Lavras, Avenida Dr. Sylvio Menicucci, 1001, Kennedy, Lavras, Brazil, $37200000,{ }^{2}$ Institute of Agricultural Sciences, Federal University of Viçosa, Km 7, Zona Rural, MG-230-Rodoviário, Rio Paranaíba, Brazil, 38810000

\section{A B S TR A C T}

One of the main products extracted from seeds is the oil, which have great importance in human food. They help in the absorption of fat-soluble vitamins and antioxidants. The oil extraction process can be carried out in different ways, being one of them the solvent extraction. Ethanol is a solvent with the potential to replace hexane, which is a renewable and non-toxic solvent. However, the oil shows low solubility in ethanol, and it is important to study cosolvents that may improve the solubility and yield of the oil extraction. A response surface methodology (RSM) was applied to optimize the ethanolic extraction using cosolvents. The soluble solids yield and the retention index from pequi and murici seeds extraction using ethanol and cosolvents (hexane and isopropanol) were estimated. Soluble solids greatest recovery was with $10 \%$ of each cosolvent at $45^{\circ} \mathrm{C}$, for both pequi and murici seeds. The low retention index obtained represents a greater efficiency in the extraction process, however, the empirical model did not describe this variable for murici seeds; and it was independent from the cosolvents mass fraction concerning the pequi almonds. Temperature was a parameter with high influence on the recovery of soluble solids and retention index of pequi and murici seeds solid-liquid extraction process. This paper provides a comprehensive approach to murici and pequi seeds waste oil production from an industrial perspective, by using biorenewable solvents, such as ethanol.

Keywords: Caryocar brasiliense; Byrsonima crassifolia; Solid-liquid extraction; Renewable solvents; Residue exploitation

\section{INTRODUCTION}

Brazil is a country that deserves to be highlighted by the significant biological diversity, including of nutritive plant species (Deus et al., 2012). One of the biomes that contribute significantly to this diversity is the Cerrado. The Brazilian Cerrado is the second largest biome in the country, covering 2 million $\mathrm{km}^{2}$ in the states of Goiás, Tocantins, Mato Grosso, Mato Grosso do Sul, the Federal District, and areas of São Paulo, Minas Gerais, Maranhão, Piauí, and Bahia, which is equivalent to approximately $25 \%$ of the country (Moraes, 2018). Guimarães et al. (2004) reported the need for research and development of technologies related to a better use of the species found in Cerrado, since they may be potential sources of economic exploitation. Several native fruits from Cerrado have been gained interest by the scientific community due to their exotic flavor, nutritional value, and relevant content of functional compounds (Oliveira et al., 2012; Bailão et al.,
2015; Cândido and Silva, 2017; Araújo et al., 2018), such as pequi and murici.

Pequi (Caryocar brasiliense Camb.) fruit is the target of the most varied studies, considered a fruit of exotic flavor and aroma that has an edible almond whose composition deserves to be highlighted by its high lipid content $(\sim 50 \%$ d.b.) (Lima et al., 2007; Sousa et al., 2011; Luzia and Jorge, 2013; Araújo et al., 2018). Therefore, pequi almond is a potential source for oil extraction. Also, the outlet of this process is a defatted biomass with high protein content, which may perform a relevant nutritive role if applied in food products, once it is free of solvent residue.

Murici (Byrsonima crassifolia) is a fruit consumed mainly fresh, such as pequi. It has a soft pulp, but it can also be consumed in other ways, such as juices, jellies, sorbets, and liqueurs (Alves and Franco, 2003). Studies involving this fruit and, especially, its seeds (which are usually discarded as waste) are limited.

\footnotetext{
${ }^{*}$ Corresponding author:

Érica Resende Oliveira, Department of Food Science, Federal University of Lavras, Avenida Dr. Sylvio Menicucci, 1001, Kennedy, Lavras, Brazil, 37200000. Tel.: +55 62 981039113. E-mail: erica_le@hotmail.com
} 
One of the main products extracted from seeds is the oil, which have great importance in human food. They help in the absorption of fat-soluble vitamins and antioxidants, they also are sources of fatty acids, some considered essential for the proper functioning of the human body by providing energy (Welte and Gould, 2017). The oil extraction process can be carried out in different ways, being one of them the solvent extraction. Solvent extraction is taken as a mass transport process from one phase to another, wherein a liquid solvent is responsible for extracting components contained in a solid matrix. When the solvent phase is introduced into the system, it is continuously enriched with the component being extracted, until a steady state is reached, this operation is known as solid-liquid extraction or leaching. The final quality of the obtained oil can be influenced by some factors, such as the co-extraction of the non-lipid components and the undesired oxidation. Therefore, special care is needed with some samples to obtain the lipid fraction, such as the solvent selection, which is an important step to be taken into account in the solid-liquid extraction process, once it influences the yield, the extract composition, and its sensory qualities (Pellerin and Danisco, 2001; Araújo et al., 2018).

A range of solvents have been used in order to remove oil from seeds, but hexane is one of the most popular solvent employed in industrial processes. Hexane is a petroleum distillate containing a mixture of hexane isomers with a boiling range of 65 to $71^{\circ} \mathrm{C}$, which may present from 45 to $70 \%$ n-hexane. (Gonçalves et al., 2016; Hammond et al., 2005). It presents several features favorable to the oil extraction process, such as high stability and selectivity, low corrosion, narrow boiling range, low residual oil content, better odor of the defatted meal, and the fact that it is partially immiscible with water (Cheng et al., 2018). Nevertheless, there are negative points associated to it, such as high toxicity, flammability, and explosiveness, besides being of fossil origin (Wan et al., 1995; Hanmoungjai et al., 2000; Cheng et al., 2018). Such disadvantages justify the study of alternatives to its use (Araújo et al., 2018).

Some substitutes for hexane have been studied in the extraction process, including acetone, ethanol, and isopropanol (Toma et al., 2001; Gallegos-Infante et al., 2003; Li et al., 2004; Rout et al., 2007; Proestos and Komaitis, 2008; Cuevas et al., 2009; Zaixiang et al., 2010; Rodríguez-Rojo et al., 2012; Hu et al., 2016). Polar solvents can infiltrate the cell walls, allowing the extraction of substances that would not be extracted by apolar ones. As a result, these are the most favorable biorenewable solvents in order to extract oil (Baiano and Del Nobile, 2016; Tir et al., 2012). The same authors mention that ethanol and isopropanol are possible alternative solvents, also in reason to their operational safety. Wakelyn and Wan (2005) reported that ethanol and isopropanol were studied in the 80 s as potential substitutes for hexane. According to these authors, the solvents presented technical feasibility in terms of extraction yield, but did not present economic viability in the region where most of the studies were concentrated. In Brazil, the reality is different. There is a high availability of ethanol at low cost, which places the country in a privileged position in the elimination of the use of petroleum derivatives in oilseed processing (Araújo et al., 2018). In addition, ethanol is a renewable source, which is able to yield high quality oil with low free fatty acids content, and to remove antinutrients, such as gossypol, aflatoxins, and chlorogenic acids (Hron et al., 1982). It is also reported that extractions carried with ethanol yield greater content of sugar, phospholipids, pigments, waxes, and compounds that confer bitterness to the biomass (Beckel et al., 1948; Johnson and Lusas, 1983; Fonseca and Regitano-d'Arce, 1993). Isopropanol can also be acknowledged as a potential alternative to hexane (Araújo et al., 2018). In addition, some authors highlighted this solvent as a better option in relation to ethanol, once the extracted oil is more stable to oxidation (Araújo et al., 2018). Further, ethanol has higher heat of vaporization than isopropanol, resulting in a higher energy expenditure in the recovery stage of the solvent by evaporation, and in the disolventization of the cake, also, concentrated isopropanol can hold $48 \%$ of oil in solution with the alcohol, and a constant boiling azeotrope can hold only 12 to 14\% of oil (Lusas et al., 1991).

Despite their economic relevance and increasing utilization possibilities, there is a lack of available data and information on pequi and murici seeds oil extraction using solvents. In this work, a response surface methodology (RSM) was applied to optimize the ethanolic extraction. This approach permits reducing the number of experiments and assessing, at the same time, the effect of each parameter (cosolvents and temperature), and that of interactions between them on the extraction efficiency (Mané et al., 2007). The extraction yield of soluble solids from pequi and murici seeds using ethanol and cosolvents (hexane and isopropanol) was estimated, also the retention index (RI), which is represented by $\mathrm{kg}$ of adhered solution/kg of insoluble solids.

\section{MATERIALS AND METHODS}

\section{Materials}

Pequi (Caryocar brasiliense Camb.) and murici (Byrsonima crassifolia) fruits were provided by local cooperatives (Lavras, Minas Gerais, Brazil). Solvents (99\%) and other chemicals (analytical grade) were supplied by Sigma-Aldrich (São Paulo, Brazil). 


\section{Sample preparation}

Fruits were harvested in 2017. They were handpicked and immediately sent, in appropriate containers, to the Vegetable Processing Plant from the Federal University of Lavras (Lavras, MG, Brazil), properly sanitized, and stored at $-18^{\circ} \mathrm{C}$ until further processing. The fruits were defrosted, manually pulped, and the seeds were dried in a vacuum oven at 45 ${ }^{\circ} \mathrm{C}(48 \mathrm{~h})$ (absolute pressure $\left.=16.8 \mathrm{kPa}\right)($ Tecnal, TE-395, Piracicaba, Brazil). Dried seeds were ground in a mechanical multipurpose mill (Tecnal, TE-631/3, Piracicaba, Brazil) and sieved. Samples were then stored in desiccators and used for solvent extraction. The seeds characterization is available in the study carried out by Araújo et al. (2018). The proximal composition, in dry basis (d.b.), found for pequi and murici, respectively, were 50.0 and $15.0 \%$ of lipid, 33.3 and $8.8 \%$ of protein, 5.8 and $2.2 \%$ of ash, 5.0 and $27.5 \%$ of crude fiber, and 5.7 and $46.4 \%$ of carbohydrates.

\section{Solid-liquid extraction}

The extraction process was executed in an incubator (Marconi, MA830/A, Piracicaba, Brazil) (120 rpm) using solvent mixtures, at constant temperature. A sample of $5 \mathrm{~g}$ of dry seeds and $25 \mathrm{~g}$ of solvent were placed into the extractor and the process was carried for $16 \mathrm{~h}$, time needed to achieve the equilibrium according with preliminary studies. After $16 \mathrm{~h}$, tubes were centrifuged (Fanem, Excelsa II/B-206, Piracicaba, Brazil) (3000 rpm), kept under a water bath to reach the equilibrium temperature, and the extract phase (EP) of the samples were collected using microsyringes. Samples of the EP and of the raffinate phase (RP) were placed in Petri dishes, weighed, and put in a drying oven $(16.8 \mathrm{kPa}$; Tecnal, TE-395, Piracicaba, Brazil) at $60{ }^{\circ} \mathrm{C}$, until constant weight. Solvent mass in the EP $\left(\mathrm{m}_{2, \mathrm{EP}}\right)$ and RP $\left(\mathrm{m}_{2, \mathrm{RP}}\right)$ were determined by weight difference. Further, the solvent mass fraction in $\mathrm{EP}\left(\mathrm{W}_{2, \mathrm{EP}}\right)$, and the solvent mass fraction in $\mathrm{RP}\left(\mathrm{W}_{2, \mathrm{RP}}\right)$ were calculated (Equations 1 and 2).

$$
\begin{aligned}
W_{2, E P} & =\frac{m_{2, E P}}{m_{E P}} \\
W_{2, R P} & =\frac{m_{2, R P}}{m_{R P}}
\end{aligned}
$$

Where $\mathrm{m}_{2, \mathrm{EP}}$ and $\mathrm{m}_{2, \mathrm{RP}}$ are the mass of solvent in the respective phase, and $\mathrm{m}_{\mathrm{EP}}$ and $\mathrm{m}_{\mathrm{RP}}$ are the sample masses of EP and RP withdrawn, respectively.

The insoluble solids mass fraction in EP $\left(\mathrm{W}_{3, \mathrm{EP}}\right)$ was considered to be zero and the soluble solids mass fraction in $\mathrm{EP}\left(\mathrm{W}_{1, \mathrm{EP}}\right)$ was calculated according with Equation 3.

$$
W_{1, E P}=1-W_{2, E P}
$$

The mass of the mixture (solvent and seeds) $\left(\mathrm{M}_{\text {mixture }}\right)$, and the mass fraction of each component in the mixture are known variables. The remaining variables - EP mass $\left(\mathrm{M}_{\mathrm{EP}}\right)$, RP mass $\left(\mathrm{M}_{\mathrm{RP}}\right)$, soluble solids mass fraction in $\mathrm{RP}\left(\mathrm{W}_{1, \mathrm{RP}}\right)$, and insoluble solids mass fraction in $\mathrm{RP}\left(\mathrm{W}_{3, \mathrm{RP}}\right)$ - were determined through mass balance. The global mass balance is defined by Equation 2 .

$$
M_{\text {mixture }}=M_{\text {seed }}+M_{\text {solvent }}=M_{E P}+M_{R P}
$$

The soluble solids ( $\mathrm{i}=1)$, solvent $(\mathrm{i}=2)$, and insoluble solids $(i=3)$ mass balances are given by Equation 5 .

$W_{i, m i x t u r e} M_{m i x t u r e}=W_{i, E P} M_{E P}+W_{i, R P} M_{R P}$

And $W_{i}$ is defined by Equation 6, where $M_{i}$ is the mass of a given component in the EP or RP $\left(\mathrm{M}_{\mathrm{P}}\right)$.

$$
W_{i}=\frac{M_{i}}{M_{P}}
$$

The soluble solids transference in the extraction process $\left(\Gamma_{1}\right)$ was determined using Equation 7 (Rodrigues et al., 2010).

$$
{ }_{1}(\%)=100\left(\frac{W_{1, E P} M_{E P}}{W_{1, \text { seed }} M_{\text {seed }}}\right)
$$

Where, $\mathbb{W}_{1, \text { seed }}$ is the mass fraction of soluble solids or lipid in the seeds, which was obtained through Soxhlet extraction (Araújo et al., 2018).

The retention index (RI), which corresponds to the mass of the solution adhered by mass of insoluble solids in the $\mathrm{RP}$ was determined according with equation 8 .

$$
\mathrm{R} I=\left(\frac{M_{\mathrm{RP}}}{M_{3, \text { mixture }}}-1\right)
$$

Where, $M_{3, \text { mixture }}$ is the mass of insoluble solids in the mixture.

\section{Experimental design and statistical analysis}

The impacts of the operating variables (temperature and cosolvent) on pequi and murici seeds soluble solids recovery $\left(\Gamma_{1}\right)$ and retention index $(\mathrm{RI})$ were analyzed by means of experimental design. The proposed extraction process was modeled using CCRD (Central Composite Rotational Design) and RSM, and statistically tested using the analysis of variance (ANOVA) using Statistica 8.0 (StatSoft Inc., 2010). 
The coded $\left(x_{i}\right)$ and the real values of each factor are presented in Table 1. In order to predict the optimal conditions, experimental values were fitted to an empirical second order polynomial regression model (Equation 9).

$$
\begin{aligned}
\mathrm{Y}= & \beta_{0}+\beta_{1} x_{1}+\beta_{2} x_{2}+\beta_{3} x_{3}+\beta_{11} x_{1}^{2}+\beta_{22} x_{2}^{2} \\
& +\beta_{33} x_{3}^{2}+\beta_{12} x_{1} x_{2}+\beta_{13} x_{1} x_{3}+\beta_{23} x_{2} x_{3}+\beta_{123}
\end{aligned}
$$

Where, is the response function $\left(\Gamma_{1}\right.$ or $\left.\mathrm{RI}\right), \chi_{i}(i=1,2,3)$ is the studied variable, $\beta_{0}$ is the constant term, $\beta_{i}$ is the linear coefficient, $\beta_{\mathrm{ii}}$ and $\beta_{\mathrm{ij}}$ are the quadratic and interactive terms, respectively. The effect of the mass fraction of hexane $\left(x_{i}\right.$; $\% \mathrm{w} / \mathrm{w})$, and isopropanol $\left(x_{2} ; \% \mathrm{w} / \mathrm{w}\right)$ in the solvent ethanol, and of the extraction temperature $\left(x_{3}{ }^{\circ} \mathrm{C}\right)$ were studied. A complete factorial $\left(2^{3}\right)$ with two levels (+1 and -1$)$, two axial points, and three central points was applied (Table 1). In addition to the functions of $\Gamma_{1}$ and RI for murici and pequi seeds, a model for desirability was generated, taking into account high values for $\Gamma_{1}$ and low values for RI.

\section{RESULTS AND DISCUSSION}

\section{Extraction recovery yield}

Experimental data including the design matrix and responses are shown in Table 1. Regarding the soluble solids extraction, the mass fraction of hexane in ethanol $\left(x_{i}\right)$, the mass fraction of isopropanol in ethanol $\left(x_{2}\right)$, and the temperature $\left(x_{3}\right)$ were set as independent variables. The changing parameters of the solvent extraction affected pequi and murici seeds recovery yields. The maximum soluble solids recovery from pequi seeds was $84.45 \%$ (run 3) (42.2 $\mathrm{g}$ of soluble solids/100 $\mathrm{g}$ of dry seeds), however the experiment 12 exhibited very similar recovery (84.19\%). Murici seeds also presented maximum yield for experiment 12 (13.33 g of soluble solids/100 g of dry seeds). Both seeds exhibited the minimum soluble solids transfer for experiment 15 , where $10 \%$ of each cosolvent was applied at $30^{\circ} \mathrm{C}$, which was the lowest temperature employed. The highest recovery was achieved at 45 and $53.92{ }^{\circ} \mathrm{C}$, trend that was expected, once the higher the temperature, the higher is the solubilization of solids in the solvent, allowing a more efficient extraction. In this study, higher values than the soybean oil yield $(\sim 20 \%$ ) (Garcia et al., 2007$)$ in the food industry were obtained, showing that the extracts investigated can have great relevance in an industrial scale. The soluble solids recovery from pequi seeds was even greater than the results observed by Garcia et al. (2007) for other cerrado seeds (hexane-extracted), such as amburana (Amburana cearensis (Fr. Allem) A. C. Smith) $(21.5 \%$ d.b.) and baru (Dypterix alata Vog.) (37.6\% d.b.). In a previous study, carried out by Meziane et al. (2009), soluble solids from olive cake were extracted using ethanol. They evaluated the effect of solid-liquid ratio (SLR), temperature, time, and particle size, and came to a conclusion that the best SLR was $1: 5(\mathrm{w} / \mathrm{w})$ at $40^{\circ} \mathrm{C}$, which are similar parameters to the ones where the higher recovery yields were obtained in this work. In addition, the best particle size was $0.69 \mathrm{~mm}$, and the extraction time was of $20 \mathrm{~min}$, which is much lower than the period applied to carry out this study, and could explain the lower yield value reported by the authors $(3.1 \%$ d.b.), which could also be due to the low soluble solids content of the matrix (6.5\% d.b.). Martins et al. (2013) extracted

Table 1: Design matrix for the solid-liquid extraction of soluble solids from pequi and murici seeds, response values of soluble

\begin{tabular}{|c|c|c|c|c|c|c|c|}
\hline \multirow[t]{2}{*}{ Experiment } & \multirow[t]{2}{*}{$\chi_{1}$} & \multirow{2}{*}{$\chi_{2}$} & \multirow{2}{*}{$\chi_{3}$} & \multicolumn{2}{|c|}{ Pequi } & \multicolumn{2}{|c|}{ Murici } \\
\hline & & & & $\Gamma_{1}(\%)$ & $\mathbf{R I}$ & $\Gamma_{1}(\%)$ & $\mathbf{R I}$ \\
\hline 1 & $-1(4.05)$ & $-1(4.05)$ & $-1(36.08)$ & $58.03 \pm 1.53$ & $1.76 \pm 0.04$ & $57.53 \pm 0.34$ & $0.89 \pm 0.0$ \\
\hline 2 & $-1(4.05)$ & $1(15.95)$ & $1(53.92)$ & $63.58 \pm 2.48$ & $1.65 \pm 0.14$ & $68.48 \pm 0.02$ & $0.89 \pm 0.01$ \\
\hline 3 & $1(15.95)$ & $-1(4.05)$ & $1(53.92)$ & $84.45 \pm 3.68$ & $1.79 \pm 0.60$ & $70.81 \pm 0.1$ & $0.82 \pm 0.01$ \\
\hline 4 & $1(15.95)$ & $1(15.95)$ & $-1(36.08)$ & $64.37 \pm 0.34$ & $1.88 \pm 0.01$ & $67.75 \pm 0.03$ & $0.82 \pm 0.01$ \\
\hline 5 & $0(10)$ & $0(10)$ & $0(45)$ & $72.76 \pm 0.31$ & $1.29 \pm 0.0$ & $66.84 \pm 0.06$ & $0.81 \pm 0.0$ \\
\hline 6 & $-1(4.05)$ & $-1(4.05)$ & $1(53.92)$ & $64.96 \pm 0.01$ & $1.78 \pm 0.01$ & $71.28 \pm 1.03$ & $0.87 \pm 0.07$ \\
\hline 7 & $-1(4.05)$ & $1(15.95)$ & $-1(36.08)$ & $62.49 \pm 0.28$ & $1.80 \pm 0.24$ & $65.89 \pm 3.01$ & $0.88 \pm 0.04$ \\
\hline 8 & $1(15.95)$ & $-1(4.05)$ & $-1(36.08)$ & $73.07 \pm 2.37$ & $1.63 \pm 0.26$ & $69.66 \pm 0.01$ & $0.89 \pm 0.0$ \\
\hline 9 & $1(15.95)$ & $1(15.95)$ & 1 (53.92) & $82.48 \pm 0.78$ & $1.23 \pm 0.27$ & $78.37 \pm 0.41$ & $0.88 \pm 0.01$ \\
\hline 10 & $0(10)$ & $0(10)$ & $0(45)$ & $76.61 \pm 0.01$ & $1.30 \pm 0.01$ & $68.20 \pm 0.01$ & $1.12 \pm 0.02$ \\
\hline 11 & $-1.618(0)$ & $0(10)$ & $0(45)$ & $59.27 \pm 0.09$ & $1.29 \pm 0.01$ & $68.28 \pm 0.06$ & $0.88 \pm 0.0$ \\
\hline 12 & $1.618(20)$ & $0(10)$ & $0(45)$ & $84.19 \pm 3.33$ & $1.23 \pm 0.23$ & $88.86 \pm 1.28$ & $0.81 \pm 0.03$ \\
\hline 13 & $0(10)$ & $-1.618(0)$ & $0(45)$ & $64.21 \pm 4.36$ & $1.34 \pm 0.28$ & $62.13 \pm 1.48$ & $1.11 \pm 0.02$ \\
\hline 14 & $0(10)$ & $1.618(20)$ & $0(45)$ & $59.95 \pm 2.46$ & $1.62 \pm 0.27$ & $68.44 \pm 0.03$ & $1.27 \pm 0.02$ \\
\hline 15 & $0(10)$ & $0(10)$ & $-1.618(30)$ & $49.39 \pm 0.22$ & $1.83 \pm 0.01$ & $45.70 \pm 1.03$ & $1.01 \pm 0.03$ \\
\hline 16 & $0(10)$ & $0(10)$ & $1.618(60)$ & $70.54 \pm 0.52$ & $1.70 \pm 0.06$ & $75.23 \pm 7.96$ & $0.82 \pm 0.09$ \\
\hline 17 & $0(10)$ & $0(10)$ & $0(45)$ & $76.29 \pm 0.04$ & $1.19 \pm 0.01$ & $69.84 \pm 0.05$ & $1.05 \pm 0.02$ \\
\hline
\end{tabular}
solids transfer $\left(\Gamma_{1}\right)$ and retention index (RI)

$\chi_{I}$ :Mass fraction of hexane in the solvent ethanol (\%), $\chi_{2:}$ Mass fraction of isopropanol in the solvent ethanol (\%) $\chi_{2}$ Temperature $\left({ }^{\circ} \mathrm{C}\right)$ 
the oil from pequi pulp and seeds by maceration at room temperature, using hexane as the solvent, and reported yields

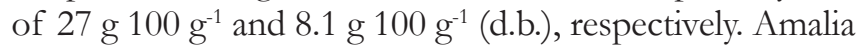
Kartika et al. (2013) studied the oil extraction process from jatropha (Jatropha curcas) seeds using hexane in a Soxhlet apparatus (6 h); obtaining an average yield of 39.4\% (d.b.), which is lower than the minimum value found in this study for both pequi and murici seeds.

The significance of the model was evaluated through ANOVA as well as the variables and their individual and mutual effects. ANOVA consists of classifying and crossclassifying statistical results and testing whether the means of a specified classification differ significantly (Oliveira et al., 2012). Table 2 shows the ANOVA results for $\Gamma_{1}$ from both seeds, and presents the significance of each variable, the $p$ values and the $t$ values of each factor.

In Equations 10 and 11, $\Gamma_{\text {Pequi }}$ and $\Gamma_{\text {Murici }}$ are responses which represent soluble solids transfer $\left(\Gamma_{1}(\%)\right)$ from pequi and murici seeds, respectively.

$$
\begin{aligned}
\Gamma_{\text {Pequi }}(\%)= & 74.37+7.22 x_{1}+0.27 x_{1}^{2}-1.09 x_{2} \\
& -3.42 x_{2}^{2}+5.42 x_{3}^{2}-4.23 x_{3}^{2} \\
& -1.72 x_{1} x_{2}+2.68 x_{1} x_{3}+0.11 x_{2} x_{3}
\end{aligned}
$$

$$
\begin{aligned}
\Gamma_{\text {Murici }}(\%)= & 68.20+4.28 x_{1}+4.09 x_{1}^{2}+1.62 x_{2} \\
& -0.98 x_{2}^{2}+5.73 x_{3}-2.82 x_{3}^{2} \\
& +0.01 x_{1} x_{2}-0.57 x_{1} x_{3}-0.21 x_{2} x_{3}
\end{aligned}
$$

The variation in responses determined by the quadratic regression model is expressed by the determination coefficient $\left(\mathrm{R}^{2}\right)$. Experimental results versus predicted results for $\Gamma_{1}(\%)$ are shown in Figure 1.
Predicted results, which correspond to the complete model (including the non-significant parameters), closely matched the experimental ones as the model explains 91 and 84\% of the variability among sample, for pequi and murici $\Gamma_{1}$ $(\%)$ results, respectively. $\mathrm{R}^{2}>70 \%$ indicates the quality of the model in relation to its predictability of responses and experimental significance. Variation coefficients (CV) were found to be 3.1 and 2.2\% for pequi and murici seeds, respectively. Low CVs $(<10 \%)$ clearly indicate a high degree of predictability regarding experimental responses and a good deal of reliability regarding the experimental data (Lestander and Samuelsson, 2010). In the case of a quadratic model, other parameters should be evaluated other than the $\mathrm{R}^{2}$ and $\mathrm{CV}$ in order to study the significancy of the model, such as the F-value $\left(\mathrm{F}_{\text {Regression/Residue }}\right.$ and $\left.\mathrm{F}_{\text {Lack of fit/Pure error }}\right)$, which indicates the significance of each controlled factor on each tested model (Oliveira et al., 2012), the residual standard error, the independency and the normality of the residues, and also the analytical discernment of the scientist should be taken into account. Concerning the pequi responses for $\Gamma_{1}$, the calculated $\mathrm{F}_{\text {Regression/Residue }}(7.58)$ was higher than the $\mathrm{F}_{\text {Tabulated }}$ (3.68), however, the $\mathrm{F}_{\text {Lack of fit/Pure error }}(6.15)$ was higher than the $\mathrm{F}_{\text {Tabulated }}$ value. Inspite of this last paremeter not being significant, the other ones were, such as the low residual standard error (Table 2), and the normality and independency of residues (Figure 1). Thus, the model (Equation 10) is significant and able to describe the $\Gamma_{1}$ from pequi almonds. For murici seeds responses, the $\mathrm{F}_{\text {Regression/Residue }}$ (4.22) and the $\mathrm{F}_{\text {Lack of fit/Pure error }}(17.04)$ were also higher than the $\mathrm{F}_{\text {Tabulated }}(3.68)$, meaning that only the first was significant. However, all of the other parameters complied to the requisites of significance of the model (Equation 11). These analyzes made it possible to

\begin{tabular}{|c|c|c|c|c|c|c|c|c|c|c|}
\hline \multirow[t]{2}{*}{ Source } & \multicolumn{2}{|c|}{ Sum of square } & \multicolumn{2}{|c|}{ Degree of freedom } & \multicolumn{2}{|c|}{ Mean square } & \multicolumn{2}{|c|}{$T$} & \multicolumn{2}{|c|}{$p$-value } \\
\hline & Pequi & Murici & Pequi & Murici & Pequi & Murici & Pequi & Murici & Pequi & Murici \\
\hline$\chi_{1}$ & 690.9421 & 242.9650 & 1 & 1 & 690.9421 & 242.9650 & 151.3796 & 107.6718 & $0.0065^{\star}$ & $0.0092^{*}$ \\
\hline$\chi_{1}^{2}$ & 0.7342 & 171.4320 & 1 & 1 & 0.7342 & 171.4320 & 0.1609 & 75.9714 & 0.7272 & $0.0129^{*}$ \\
\hline$\chi_{2}$ & 15.8470 & 34.6633 & 1 & 1 & 15.8470 & 34.6633 & 3.4719 & 15.3613 & 0.2034 & 0.0594 \\
\hline$\chi_{2}^{2}$ & 119.5761 & 9.8631 & 1 & 1 & 119.5761 & 9.8631 & 26.1981 & 4.3709 & $0.0361^{*}$ & 0.1717 \\
\hline$\chi_{3}$ & 388.7392 & 435.1230 & 1 & 1 & 388.7392 & 435.1230 & 85.1695 & 192.8281 & $0.0115^{*}$ & $0.0051^{*}$ \\
\hline$\chi_{3}^{2}$ & 182.7778 & 81.5483 & 1 & 1 & 182.7778 & 81.5483 & 40.0451 & 36.1388 & $0.0241^{*}$ & $0.0266^{*}$ \\
\hline$\chi_{2} \chi_{1}$ & 23.6328 & 0.0010 & 1 & 1 & 23.6328 & 0.0010 & 5.1778 & 0.0004 & 0.1507 & 0.9850 \\
\hline$\chi_{1} \chi_{3}$ & 57.6201 & 2.6106 & 1 & 1 & 57.6201 & 2.6106 & 12.6241 & 1.1569 & 0.0709 & 0.3946 \\
\hline$\chi_{2} \chi_{3}$ & 0.0990 & 0.3570 & 1 & 1 & 0.0990 & 0.3570 & 0.0217 & 0.1582 & 0.8964 & 0.7292 \\
\hline Lack of fit & 140.2917 & 192.2918 & 5 & 5 & 28.0583 & 38.4584 & 6.1473 & 17.0431 & 0.1458 & 0.0563 \\
\hline Pure error & 9.1286 & 4.5131 & 2 & 2 & 4.5643 & 2.2565 & & & & \\
\hline Total & 1606.8274 & 1264.3894 & 16 & 16 & & & & & & \\
\hline Residual standard error & 5.21 & 5.20 & & & & & & & & \\
\hline
\end{tabular}
validate empirical coded models (Equations 10 and 11) and build the RS presented in Figure 2.

The variable temperature $\left(x_{3}\right)$ (linear and quadratic) presented the lowest $\mathrm{p}$ values for both $\Gamma_{1}$. The significance

Table 2: ANOVA for the response surface quadratic model of soluble solids transfer $(\Gamma 1)$ from pequi and murici seeds 


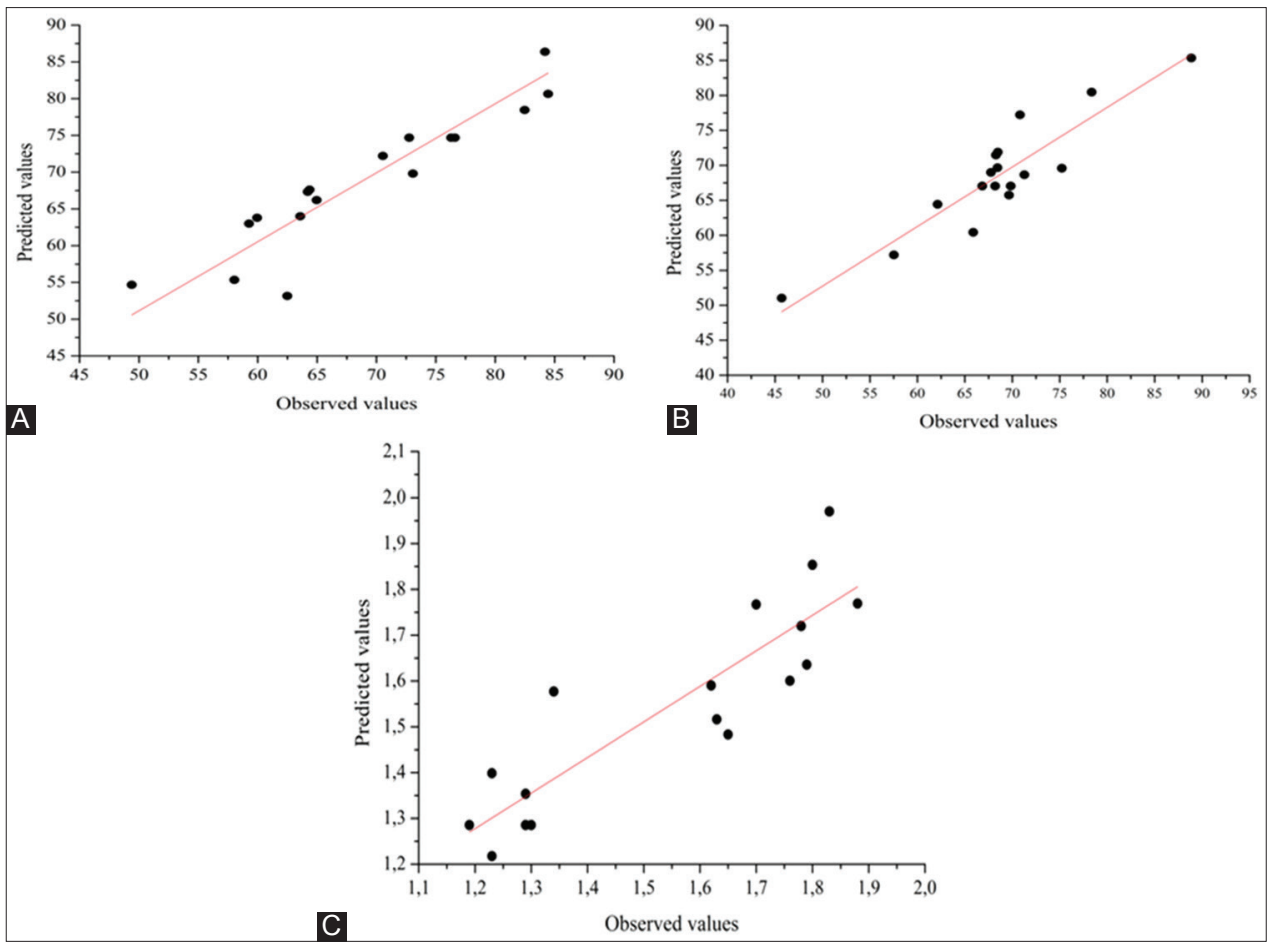

Fig 1. Experimental versus predicted results for pequi (A) and murici (B) soluble solids extraction yield and retention index for pequi extraction (C).

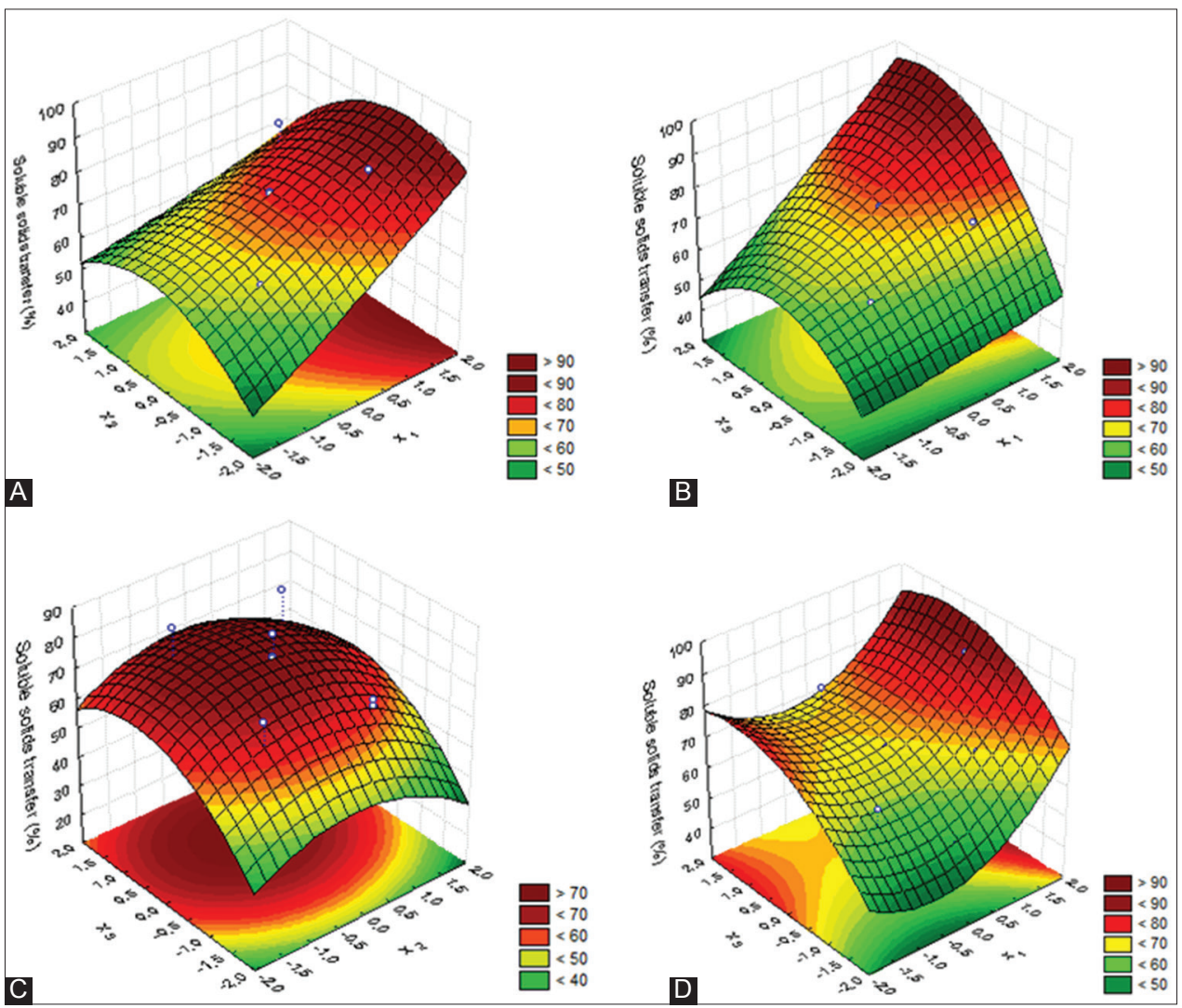

Fig 2. Response surface plots for soluble solids extraction $\left(\Gamma_{1}(\%)\right)$ from pequi and murici seeds, where the omitted variable was fixed at the central point. (A), (B), (C) $\Gamma_{1}(\%)$ for pequi almonds; (D) $\Gamma_{1}(\%)$ for murici seeds.

of the negative quadratic term indicates that there is a point of maximum for this variable. A different trend was observed by Oliveira et al. (2012) in their study involving the optimization of oil extraction from rice bran with hydrated 
Table 3: ANOVA $(p<0.05)$ for the response surface quadratic model of RI

\begin{tabular}{|c|c|c|c|c|c|c|c|c|c|c|}
\hline \multirow[t]{2}{*}{ Factor } & \multicolumn{2}{|c|}{ Sum of square } & \multicolumn{2}{|c|}{ Degree of freedom } & \multicolumn{2}{|c|}{ Mean square } & \multicolumn{2}{|c|}{ 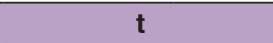 } & \multicolumn{2}{|c|}{ p-value } \\
\hline & Pequi & Murici & Pequi & Murici & Pequi & Murici & Pequi & Murici & Pequi & Muric \\
\hline$\chi_{1}$ & 0.0234 & 0.0041 & 1 & 1 & 0.0234 & 0.0041 & 6.3370 & 0.1555 & 0.1282 & 0.7314 \\
\hline$\chi_{1}^{2}$ & 0.0163 & 0.0766 & 1 & 1 & 0.0163 & 0.0766 & 4.4080 & 2.8962 & 0.1706 & 0.2309 \\
\hline$\chi_{2}$ & 0.0002 & 0.0051 & 1 & 1 & 0.0002 & 0.0051 & 0.0574 & 0.1916 & 0.8329 & 0.7044 \\
\hline$\chi_{2}^{2}$ & 0.1572 & 0.0210 & 1 & 1 & 0.1572 & 0.0210 & 42.4985 & 0.7942 & $0.0227^{*}$ & 0.4669 \\
\hline$\chi_{3}$ & 0.0521 & 0.0081 & 1 & 1 & 0.0521 & 0.0081 & 14.0786 & 0.3064 & 0.0643 & 0.6355 \\
\hline$\chi_{3}^{2}$ & 0.5547 & 0.0365 & 1 & 1 & 0.5547 & 0.0365 & 149.9262 & 1.3823 & $0.0066^{*}$ & 0.3607 \\
\hline$\chi_{2} \chi_{1}$ & 0.0061 & 0.0001 & 1 & 1 & 0.0061 & 0.0001 & 1.6351 & 0.0019 & 0.3293 & 0.9693 \\
\hline$\chi_{1} \chi_{3}$ & 0.0162 & 0.0000 & 1 & 1 & 0.0162 & 0.0000 & 4.3784 & 0.0000 & 0.1715 & 1.0000 \\
\hline$\chi_{2} \chi_{3}$ & 0.1201 & 0.0032 & 1 & 1 & 0.1201 & 0.0032 & 32.4459 & 0.1211 & $0.0295^{*}$ & 0.7611 \\
\hline Lack of fit & 0.1862 & 0.0564 & 5 & 5 & 0.0372 & 0.0113 & 10.0624 & 0.4267 & 0.0929 & 0.8086 \\
\hline Error & 0.0074 & 0.0529 & 2 & 2 & 0.0037 & 0.0264 & & & & \\
\hline Total & 1.0243 & 0.2859 & 16 & 16 & & & & & & \\
\hline $\mathrm{R}^{2}$ & 0.81 & 0.62 & & & & & & & & \\
\hline Residual standard error & 5.21 & 4.74 & & & & & & & & \\
\hline
\end{tabular}

*Significant values $(p<0.05)$

ethanol $\left(60-90^{\circ} \mathrm{C}\right.$; RSL 3.5:1 (w: w); 175 rpm), where only the linear effect (positive) for the variable temperature was significative. The authors observed that the temperature rise positively influenced only the yield of low-hydrated solvents, indicating that the moisture content in the solvent suppressed the extraction yield. The temperature can affect the solids solubility in the solvent, because it is directly correlated to the solvent density as well as to the solids vapor pressure (Turner et al., 2004).

The addition of isopropanol influenced the $\Gamma_{1}$ from pequi seeds, once the quadratic term coefficient $\left(x_{2}^{2}\right)$ was negative and significant, indicating that the elevation of isopropanol concentration initially favors the solubilization of soluble solids, reaching a maximum, and posterior addition leads to a reduction of their solubilizing power.

The linear coefficient of the variable (hexane mass fraction in ethanol) for both $\Gamma_{1}$ models exhibited positive and significative effect on the extraction. For pequi seeds the addition of hexane favored the $\Gamma_{1}$, however, the quadratic term $\left(x_{1}^{2}\right)$ was only significative for murici, and also positive, indicating that there is a point of minimum related to it, that is, the process should be operated with higher or lower concentration than this point.

Examination of the responses surfaces (RS) curves (Figure 2) enables selection of optimal conditions for extraction of the soluble solids from each of the seeds and confirms that maximum extraction is reached in the range of conditions considered.

RS was used to represent the models at the central point of the fixed variable. Figures 2 A-D show the effect of the variables on the response $\left(\Gamma_{1}(\%)\right)$ for pequi almonds and murici seeds extraction. It is inferable that the rise in temperature and hexane mass fraction influenced the $\Gamma_{1}$ $(\%)$ of both materials. For the temperature $\left(x_{3}\right)$ there is a range where the yield is maximum, and the hexane $\left(x_{1}\right)$ as a cosolvent positively influences the extraction of pequi, and for the murici seed, there is a range where the yield is minimum, thus, this cosolvent must be used out of this range of concentration (Fig 2D).

Figure 2A shows the behavior of the soluble solids yield from the pequi seeds when varying the cosolvents concentrations, where the variable $x_{3}$ (temperature) was fixed at the central point $\left(45^{\circ} \mathrm{C}\right)$. The RS demonstrates that the extraction of soluble solids shows a tendency to increase with the addition of hexane. The optimal region for this temperature is between 16 and $20 \%$ hexane and between 4 and 10\% isopropanol.

Figure $2 \mathrm{~B}$, where the variable $x_{2}$ (isopropanol mass fraction in ethanol) was fixed at the central point (10\%) represents an interesting behavior. The optimum yield can be obtained with the highest temperature and hexane fraction in ethanol. However, good yield results could also be obtained when no hexane $\left(x_{1}=-1,68\right)$ is present in the solvent solution, and temperature above the central point $\left(45^{\circ} \mathrm{C}\right)$ is applied.

Figure $2 \mathrm{C}$ shows a RS for pequi seeds, where the variable $x_{1}$ (hexane mass fraction in ethanol) was fixed at the central point $(10 \%)$ and shows the behavior of the soluble solids yield with the variation of the isopropanol mass fraction $\left(x_{2}\right)$ and temperature $\left(x_{3}\right)$ for pequi seeds. The region with the highest yield was in the range of $45{ }^{\circ} \mathrm{C}$ to $55^{\circ} \mathrm{C}$ with a mass fraction of isopropanol between 8 and $12 \%$.

As isopropanol had only a linear effect for murici, it was chosen to fix this variable in order to understand the 
influence of temperature and solvent (hexane) when adding the maximum and minimum content of isopropanol. The behavior of the soluble solids yield of murici seeds with isopropanol fixed at the central point $(10 \%)$ is presented in Figure 2D. The optimal region was characterized in these conditions when hexane mass fraction was higher than $15 \%$, increasing the recovery of soluble solids in high temperatures. As isopropanol had no effect on the yield of soluble solids from murici seeds the only curve generated was when isopropanol mass fraction was fixed.

According to Amarante et al. (2014), the temperature increase usually influences the extraction of soluble solids due to the increase of the solubility of the oil and the decrease of the viscosity of the solution, facilitating the mass transfer process. Javed et al. (2015) pointed out that further extraction may occur with increasing temperature as it may increase the kinetic energy of the solvent molecules. Although the raise of temperature promotes an increase of the solubility of the solute in the solvent, the final effect of this variable on the yield of the extract will also be influenced by its effect on the retention index (item 3.2).

\section{Retention index (RI)}

RI has a decisive impact on the number of stages carried out to complete the extraction and on the desolventization step, and it depends on the viscosity of the extract solution, and mainly on the physicochemical affinity between the solvents, cosolvents and the solid matrix (Bessa et al., 2017).

The design matrix and real values of the experiments to evaluate the effect of three variables including the mass fraction of hexane $\left(x_{1}\right)$, isopropanol $\left(x_{2}\right)$, and extraction temperature $\left(x_{3}\right)$ on $\mathrm{RI}$ are presented in Table 1.

$\mathrm{RI}$ indicates the amount of solution retained in RP, thus, the lower this index is the most efficient is the extraction. The highest RI for pequi almonds extraction process was obtained for run 4 (1.88 $\mathrm{kg}$ adhered solution $/ \mathrm{kg}$ insoluble solids), which did not present the greatest $\Gamma_{1}(64.37 \%)$, leading to conclude that RI for pequi almonds is independent on the solvent employed. The highest RI for murici seeds was of $1.27 \mathrm{~kg}$ adhered solution/ $\mathrm{kg}$ insoluble solids (run 14), corresponding to a $\Gamma_{1}$ of $68.44 \%$.

By applying multiple regression analysis on experimental data ( $p<0.05$ ), the complete quadratic model for predicting RI for pequi is presented in Equation 12.

$$
\begin{aligned}
\mathrm{RI}_{\mathrm{Pequi}} & =1.24-0.04 x_{1}+0.04 x_{1}^{2}+0.004 x_{2} \\
& +0.12 x_{2}^{2}-0.06 x_{3}+0.23 x_{3}^{2} \\
& -0.03 x_{1} x_{2}-0.04 x_{1} x_{3}-0.12 x_{2} x_{3}
\end{aligned}
$$

Through ANOVA for the response variable RI (Table 3) it was observed that no effect was significative $(p<0.05)$ for murici seeds.

Meaning that it is not possible to stablish an empirical model for this response, consequently, no response surface could be plotted. On the other hand, the model for RI of pequi almonds was highly significant $(p<0.05)$ (Equation 12; Table 3). The average RI for murici seeds was 0.93 , and for pequi almonds it was 1.55 , indicating that pequi almonds are less feasible to the solvent recovery process, once the adhered solution in the fibers (insoluble solids) are higher, making it difficult to recover the solvent from RP.

$P$ value of the lack of fit was 0.0929 , which implied that the model equation was adequate for predicting RI under any combinations of variables. The $\mathrm{R}^{2}$ was 0.81 , indicating that $81 \%$ of the variation found for the response RI could be attributed to the independent variables (Deng et al., 2017). The low CV (4.89\%) suggested a better precision and reliability of the conducted experiments. Figure 1C shows the observed and predicted values of RI for pequi seeds soluble solids extraction. This graph presents a fitting of the experimental data to the model results, and it is possible to observe that data from pequi extraction are close to the predicted values, corroborating the highly significance of the model.

The soluble solids extraction from pequi almonds had temperature $\left(x_{3}\right)$ and isopropanol $\left(x_{2}\right)$ mass fractions significantly influencing RI (Equation 12). The linear effects were not significant for any of the factors; the variables $x_{2}$ and $x_{3}$ quadratic effects were positive and significative, and, their interaction $(p=0.03$ or $p<0.05)$ was also significant, but negative. The lack of adjustment reached a calculated $\mathrm{F}$ of 10.1, which was higher than the tabulated one $(\mathrm{F}=3.7)$, and the $\mathrm{F}$ calculated for the regression $(\mathrm{F}=3.33)$ was lower than the tabulated one, in this way the mathematically obtained model could not be considered of good fit, and should be further evaluated in order to be used to represent the RI behavior in the respective experimental conditions. Another parameter that should be taken into consideration is the residual standard error, which was low for this response (Table 3). In this particular situation where not all of the parameters fitted in order to elect the model as significant, the judgment of the scientists should be regarded to not present the RS concerned with this variable.

\section{Desirability}

The ideal regions for the response variables obtained $\left(\Gamma_{1}\right.$ and RI) did not present the same optimal regions, nor their significant effects were equivalent to each other. Although a high RI in the RP indicates a trend of lower soluble solids yield in the EP, this condition was not observed in the study. 

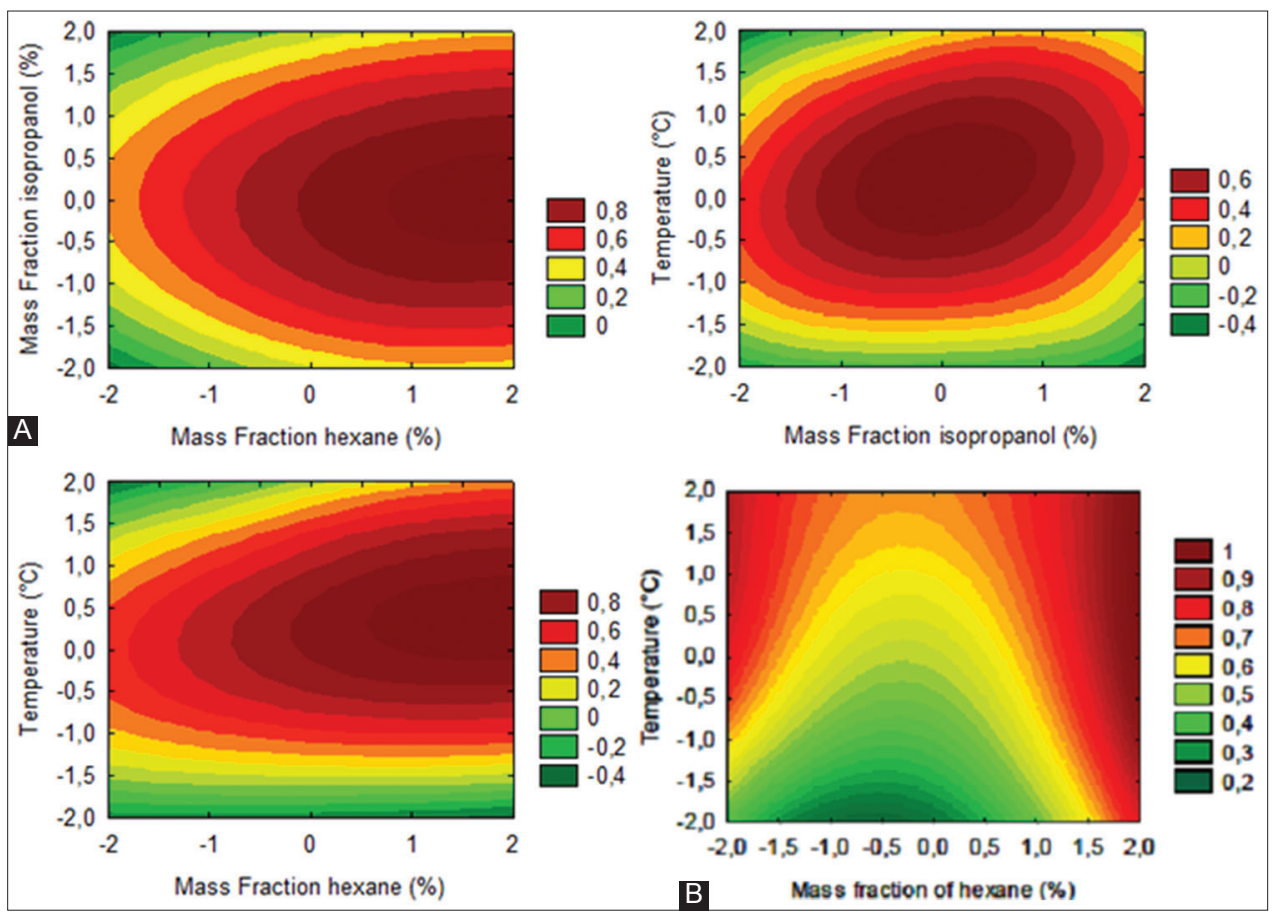

Fig 3. Desirability function contour plots for pequi seeds (A) and murici seeds (B).

A desirability function was generated using the lowest value for RI and the highest value for the response variable yield of the soluble solids extraction, where the attribute 1 was employed to represent the highest $\Gamma_{1}$ and the lowest RI, and the attribute 0 was employed to represent the lowest and the highest RI. Figure 3A shows the RS for pequi almonds, where, when evaluating $\mathrm{RI}$ and $\Gamma_{1}$, simultaneously, the region with the highest desirability was at temperatures between 42 and $48{ }^{\circ} \mathrm{C}, 15$ to $20 \%$ of hexane mass fraction in ethanol; and 45 to $50{ }^{\circ} \mathrm{C}$ with isopropanol mass fractions between 7 and $13 \%$.

The desirability function for murici seeds is presented by a contour curve fixing the isopropanol mass fraction, considering that there is no significant difference for the yield of soluble solids nor for RI (Fig 3B). The optimization of the desirability function for murici shows similarity with the curve for $\Gamma_{1}$, considering that the RI did not show any significant effect. In the region of this study it was noticed that the temperature increasing is desirable to the extraction process, with regions above $45^{\circ} \mathrm{C}$ and between 16 and $20 \%$ of hexane mass fraction.

\section{CONCLUSION}

This study allowed the comprehension of the extraction process of soluble solids from pequi and murici residues using ethanol and cosolvents. According to the experimental design and response surface analysis, quadratic polynomial models can be used to predict the transfer of soluble solids from pequi and murici seeds from experiments using ethanol as the solvent, and hexane and isopropanol as cosolvents, carried out at equilibrium conditions. The three independent variables involved in the models were the mass fraction content of each cosolvent (hexane and isopropanol) in ethanol and temperature. Within the range of the operating conditions studied, the optimal region was different for both materials. Concerning pequi almonds, the best region was between 42 and $48{ }^{\circ} \mathrm{C}$, hexane mass fraction over $15 \%$, and isopropanol in the range of 7 to $13 \%$. While for murici seeds, it is desirable to work with higher temperatures $\left(>45^{\circ} \mathrm{C}\right)$, hexane mass fraction in the range of 16 and $20 \%$, being the results independent of isopropanol mass fraction. The extraction process of pequi almonds had the temperature significantly influencing the retention index. The retention index for murici seeds extraction process could not be described by the empirical model. Thus, the extraction process of pequi almond residues using ethanol and cosolvents is more feasible than for murici seeds. Further studies are of relevance in order to understand the chemical composition of the extracts obtained, and their viability to be applied in the food or pharmaceutical industries.

\section{ACKNOWLEDGEMENTS}

The financial support for this research by FAPEMIG (CAG APQ 01689/13), the technical and fincancial support by Federal University of Lavras (UFLA), and the fellowships awarded by CAPES (Coordenação de Aperfeiçoamento 
de Pessoal de Nível Superior - Finance code 001), CNPq (Conselho Nacional de Desenvolvimento Científico e Tecnológico), and FAPEMIG (Fundação de Amparo à Pesquisa de Minas Gerais), are gratefully acknowledged by the authors.

\section{Authors' contributions}

Ana Cristina Moreira Andrade Araújo: designed, planned and executed the experiment. Gabriel Ribeiro Carvalho: designed and planned the experiment; writing and analyzing the results. Érica Resende Oliveira: designed and planned the experiment; writing and analyzing the results. Evandro Galvão Tavarez Menezes: executed the experiment, Fabiana Queiroz: designed and planned the experiment; writing and analyzing the results.

\section{REFERENCES}

Alves, G. L. and M. R. B. Franco. 2003. Headspace gas chromatography-mass spectrometry of volatile compounds in murici (Byrsonima crassifolia L. Rich). J. Chromatogr. A. 985(4): 297-301.

Amarante, R. C. A., P. M. Oliveira, F. K. Schwantes and J. A. Morón-Villarreyes. 2014. Oil extraction from castor cake using ethanol: Kinetics and thermodynamics. Ind. Eng. Chem. Res. 53(16): 6824-6829.

Araújo, A. M. A., E. G. T. Menezes, A. W. C. Terra, B. O. Dias, É. R. Oliveira and F. Querioz. 2018. Bioactive compounds and chemical composition of Brazilian cerrado fruits' wastes: Pequi almonds, murici, and sweet passionfruit seeds. J. Food Sci. Technol. (Campinas). 38(Suppl 1): 203-214.

Araújo, A. M. A., É. R. Oliveira, G. R. Carvalho, E. G. T. Menezes, B. O. Dias and F. Queiroz. 2018. Solvent effect on the extraction of soluble solids from murici and pequi seeds. J. Food Process Eng. 41(6): e12813.

Baiano, A. and M. A. Del Nobile. 2016. Antioxidant compounds from vegetable matrices: Biosynthesis, occurrence, and extraction systems. Crit. Rev. Food Sci. Nutr. 56(12): 2053-2068.

Bailão, E. F. L., I. A. Devilla, E. C. Conceição and L. L. Borges. 2015. Bioactive compounds found in Brazilian cerrado fruits. Int. J. Mol. Sci. 16(10): 23760-23783.

Beckel, A. C., P. A. Belter and A. K. Smith. 1948. Solvent effects on the products of soybean oil extraction. J. Am. Oil Chem. Soc. 25(1): 7-9.

Bessa, L. C. B., M. C. Ferreira, C. E. C. Rodrigues, E. A. C. Batista and A. J. A. Meirelles. 2017. Simulation and process design of continuous countercurrent ethanolic extraction of rice bran oil. J. Food Eng. 202: 99-113.

Cândido, T. L. N. and M. R. Silva. 2017. Comparison of the physicochemical profiles of buriti from the Brazilian cerrado and the amazon region. Food Sci. Technol. (Campinas). 37(Suppl 1): 78-82.

Cheng, M. H., J. J. K. Sekhon, K. A. Rosentrater, T. Wang, S. Jung and L. A. Johnson. 2018. Environmental impact assessment of soybean oil production: Extruding-expelling process, hexane extraction and aqueous extraction. Food Bioprod. Process. 108: 58-68.

Cuevas, M. S., C. E. C. Rodrigues and A. J. A. Meirelles. 2009. Effect of solvent hydration and temperature in the deacidification process of sunflower oil using ethanol. J. Food Eng. 95(2): 291-297.

De Deus, F. P., M. A. de Faria, E. L. de Oliveira and P. C. Neto. 2012. Jatropha seed oil content and yield under different irrigation and potassium fertilization levels. Eng. Agríc. 32(6): 1089-1096.

Deng, Z., J. Jung, J. Simonsen and Y. Zhao. 2017. Cellulose nanomaterials emulsion coatings for controlling physiological activity, modifying surface morphology, and enhancing storability of postharvest bananas (Musa acuminate). Food Chem. 232: 359-368.

Fonseca, H. and M. A. B. Regitano-d'Arce. 1993. Aflatoxin removal of peanut meals with aqueous ethanol. Sci. Agric. 50(1): 154-156.

Gallegos-Infante, J. A., R. Rico-Martínez, N. E. R. Guzmán, R. F. González-Laredo and J. M. Castro. 2003. Experimental characterization of two varieties of sunflower with potential for oil production extracted with hexane and isopropyl alcohol. Grasas Aceites. 54(3): 245-252.

Garcia, C. C., P. I. B. Franco, T. O. Zuppa, N. R. A. Filho and M. I. G. Leles. 2007. Thermal stability studies of some cerrado plant oils. J. Therm. Anal. Calorim. 87(3): 645-648.

Gonçalves, C. B., C. E. C. Rodrigues, E. C. Marcon and A. J. A. Meirelles. 2016. Deacidification of palm oil by solvent extraction. Sep. Purif. Technol. 160: 106-111.

Guimarães, E. P., J. I. Sanz, I. M. Rao, M. C. Amézquita, E. Amézquita and R. J. Thomas. (Eds.), 2004. Agropastoral Systems for the Tropical Savannas of Latin America, CIAT/EMBRAPA, Brasília (DF), Brazil.

Hammond, E. G., A. J. Lawrence, S. Caiping, T. Wang and P. J. White. 2005. Soybean oil. In: F. Shadidi (Ed.), Bailey's Industrial Oil and Fat Products. $6^{\text {th }}$ ed., John Wiley and Sons, Hoboken, New Jersey, New York.

Hanmoungjai, P., L. Pyle and K. Niranjan. 2000. Extraction of rice bran oil using aqueous media. J. Chem. Technol. Biotechnol. 75(5): 348-352.

Hron, R. J., S. P. Koltun and A. V. Graci. 1982. Biorenewable solvents for vegetable oil extraction. J. Am. Oil Chem. Soc. 59(9): 674A-684A.

Hu, C. J., Y. Gao, Y. Liu, X. Q. Zheng, J. H. Ye, Y. R. Liang and J. L. Lu. 2016. Studies on the mechanism of efficient extraction of tea components by aqueous ethanol. Food Chem. 194: 312-318.

Javed, F., S. W. Ahmad, A. Rehman, S. Zafar and S. R. Malik. 2015. Recovery of rice bran oil using solid-liquid extraction technique. J. Food Process Eng. 38(4): 357-362.

Johnson, L. A. and E. W. Lusas. 1983. Comparison of alternative solvents for oils extraction. J. Am. Oil Chem. Soc. 60(2): 229-242.

Kartika, I. A., M. Yani, D. Ariono, P. Evon and L. Rigal. 2013. Biodiesel production from jatropha seeds: Solvent extraction and in situ transesterification in a single step. Fuel. 106: 111-117.

Lestander, T. A. and R. Samuelsson. 2010. Prediction of resin and fatty acid content of biorefinery feedstock by on-line nearinfrared (NIR) spectroscopy. Energy Fuels. 24(9): 5148-5152.

Li, H., L. Pordesimo and J. Weiss. 2004. High intensity ultrasoundassisted extraction of oil from soybeans. Food Res. Int. 37(7): 731-738.

Lima, A., A. M. O. Silva, R. A. Trindade, R. P. P. Torres and J. ManciniFilho. 2007. Chemical composition and bioactive compounds in the pulp and almond of pequi fruit. Rev. Bras. Fruticultura. 29(3): 695-698.

Lusas, E. W., L. R. Watkins and S. S. Koseoglu. 1991. Isopropyl alcohol to be tested as solvent. Int. News Fats Oils Relat. Mater 2: $970-976$.

Luzia, D. M. M. and N. Jorge. 2013. Bioactive substance contents and antioxidant capacity of the lipid fraction of Annona crassiflora 
Mart. seeds. Ind. Crops Prod. 42: 231-235.

Mané, C., J. M. Souquet, D. Ollé, C. Verriés, F. Véran, G. Mazerolles and $\mathrm{H}$. Fulcrand. 2007. Optimization of simultaneous flavanol, phenolic acid, and anthocyanin extraction from grapes using an experimental design: Application to the characterization of champagne grape varieties. J. Agric. Food Chem. 55(18): 7224-7233.

Martins, P. C., L. O. Ferreira and T. S. Peixoto. 2013. Study of the process of extraction and refining of pequi (Cariocar brasiliense Camb.) oil. Engineering. 5: 73-79.

Meziane, S., H. Kadi, K. Daoud and F. Hannane. 2009. Application of experimental design method to the oil extraction from olive cake. J. Food Process. Preserv. 33(2): 176-185.

Moraes, D. 2018. Cerrado Biome. Available from: http://www.invivo. fiocruz.br/cgi/cgilua.exe/sys/start.htm?UserActiveTemplate=es panol\&infoid=1338\&sid=102. [Last retrieved on 2018 Aug 29].

Oliveira, R. C., S. T. D. Barros and M. L. Gimenes. 2013. The extraction of passion fruit oil with green solvents. J. Food Eng. 117(4): 458-463.

Oliveira, R., V. Oliveira, K. K. Aracava and C. E. C. da Rodrigues. 2012. Effects of the extraction conditions on the yield and composition of rice bran oil extracted with ethanol-a response surface approach. Food Bioprod. Process. 90(1): 22-31.

Oliveira, V. B., L. T. Yamada, C. W. Fagg and M. G. L. Brandão. 2012. Native foods from Brazilian biodiversity as a source of bioactive compounds. Food Res. Int. 48(1): 170-179.

Pellerin, P. and S. Danisco. 2001. Comparing Extraction by Traditional Solvants with Supercritical Extraction from an Economic and Environmental Standpoint. In European Meeting on Supercritical Fluids. International Society for Advancement of Supercritical Fluids.

Proestos, C. and M. Komaitis. 2008. Application of microwaveassisted extraction to the fast extraction of plant phenolic compounds. LWT Food Sci. Technol. 41(4): 652-659.

Rodrigues, C. E. C., K. K. Aracava and F. N. Abreu. 2010. Thermodynamic and statistical analysis of soybean oil extraction process using renewable solvent. Int. J. Food Sci. Technol. 45(11): 2407-2414.

Rodríguez-Rojo, S., A. Visentin, D. Maestri and M. J. Cocero. 2012. Assisted extraction of rosemary antioxidants with green solvents. J. Food Eng. 109(1): 98-103.

Rout, L., T. K. Sen and T. Punniyamurthy. 2007. Efficient CuOnanoparticle-catalyzed C-S cross-coupling of thiols with iodobenzene. Angew. Chem. Int. Ed. 46(29): 5583-5586.

Sousa, A. G. O., D. C. Fernandes, A. M. Alves, J. B. Freitas and M. M. V. Naves. 2011. Nutritional quality and protein value of exotic almonds and nut from the Brazilian savanna compared to peanut. Food Res. Int. 44(7): 2319-2325.

StatSoft Inc. 2010. STATISTICA (Data Analysis Software System) Version 10.0. StatSoft Inc., Tulsa (OK).

Tir, R., P. C. Dutta and A. Y. Badjah-Hadj-Ahmed. 2012. Effect of the extraction solvent polarity on the sesame seeds oil composition. Eur. J. Lipid Sci. Technol. 114(12): 1427-1438.

Toma, M., M. Vinatoru, L. Paniwnyk and T. J. Mason. 2001. Investigation of the effects of ultrasound on vegetal tissues during solvent extraction. Ultrason. Sonochem. 8(2): 137-142.

Turner, C., L. C. Whitehand, T. Nguyen and T. McKeon. 2004. Optimization of a supercritical fluid extraction/reaction methodology for the analysis of castor oil using experimental design. J. Agric. Food Chem. 52(1): 26-32.

Wakelyn, P. J. and P. J. Wan. 2005. Solvent extraction to obtain edible oil products. In: C. C. Akoh (Ed.), Handbook of Functional Lipids. $1^{\text {st }}$ ed., CRC Press, Boca Raton (US), pp. 89-131.

Wan, P. J., D. R. Pakarinen, R. J. Hron, O. L. Richard and E. J. Conkerton. 1995. Alternative hydrocarbon solvents for cottonseed extraction. J. Am. Oil Chem. Soc. 72(6): 653-659.

Welte, M. A. and A. P. Gould. 2017. Lipid droplet functions beyond energy storage. Biochim. Biophys. Acta Mol. Cell Biol. Lipids. 1862(10): 1260-1272.

Zaixiang, L., W. Hongxin, Z. Ming and W. Zhouping. 2010. Improved extraction of oil from chickpea under ultrasound in a dynamic system. J. Food Eng. 98(1): 13-18. 